\title{
YUCOMAT 2007 Presented Latest Trends in Materials Science and Engineering on a Small Scale \\ www.yu-mrs.org.yu
}

On September 10-14, 2007, Herceg Novi, Montenegro, was once more the host of the Yugoslav Materials Research Society (Yu-MRS) Conference: YUCOMAT 2007, sponsored by the Institute of Technical Sciences of the Serbian Academy of Sciences and Arts. The conference drew several hundred attendees from around the world to hear four plenary sessions in addition to five one-day symposia on the topics of advanced methods in materials synthesis and processing, advanced materials for high-technology applications, nanostructured materials, composites, and biomaterials. The Conference also included a Workshop on the bilateral cooperation between Slovenia and Serbia. Selected manuscripts are scheduled to appear in Materials and Manufacturing Processes, published by Taylor and Francis and Surface Engineering, published by Maney Publishing.

At the Opening Ceremony, Dragan Uskokovic, president of Yu-MRS and director of the Institute of Technical Sciences of the Serbian Academy of Sciences and Arts, gave a welcoming speech to the attendees. He said, "Following the political change which resulted in the separation of Serbia and Montenegro, last year we took some necessary steps to establish two new societies out of Yu-MRS: MRS of Serbia and MRS of Montenegro.... Good news is that we have been invited by the Federation of European Materials Research Societies to join them as soon as possible, so I expect that we will become their member possibly by the end of this year and certainly before the next Conference."

During the First Plenary Session, E. Olsson (Chalmers Univ., Stockholm, Sweden) spoke on characterization and manipulation of functional nanostructures using a high-resolution analytical transmission electron microscope (TEM) and a combined scanning probe microscope/ TEM; R. Hull (Univ. of Virginia, USA) presented controlled assembly of epitaxial nanostructures for nanoelectronic applications; S. Kodambaka (Univ. of California, Los Angeles, USA) talked about semiconductor nanowire nucleation and growth kinetics; R. Sinclair (Stanford Univ., USA) addressed recent developments in nanomaterials; D. Chatain (Research Center on Condensed Matter and NanosciencesCNRS, Marseille, France) addressed finite size effects on distribution and shape of small particles; and V. Radmilovic (Univ. of California, Berkeley, USA) lectured on novel metallic thin films for nano-electromechanical systems applications.

During the Second Plenary Session, the following talks were presented: E. Spiecker (Kiel Univ., Germany) on developments in quantitative three-dimensional (3D) structure analysis of thin solid films by TEM; E. Stach (Purdue Univ., USA) on using real time microscopy to quantitatively determine nucleation mechanisms and kinetics during the growth of Si nanowires and carbon nanotubes;

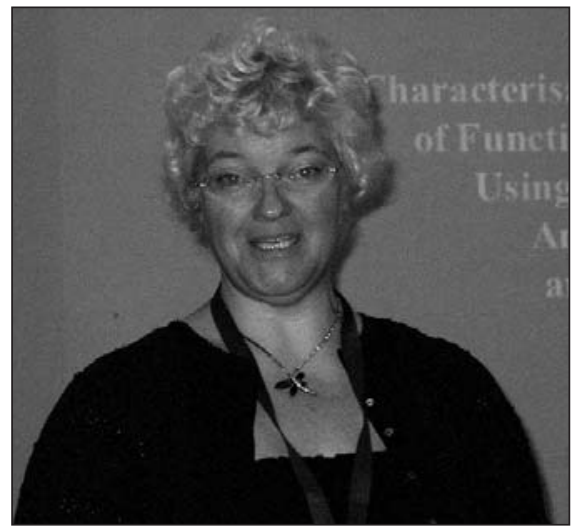

Invited speaker Eva Olsson of Chalmers University, Stockholm, Sweden, opened the First Plenary Session at YUCOMAT 2007.

H.P. Karnthaler (Univ. of Vienna, Austria) on bulk nanocrystalline alloys studied by TEM; K. Sandhage (Georgia Institute of Technology, USA) on biologically enabled assembly of nanostructured materials with complex 3D morphologies and chemistries; N. Kallay (Univ. of Zagreb, Croatia) on characterization of solid-liquid interfaces by surface potential measurements; and D. Suvorov (Jozef Stefan Institute, Ljubljana, Slovenia) on Bi-based materials for glass-free lowtemperature cofired ceramic modules. 


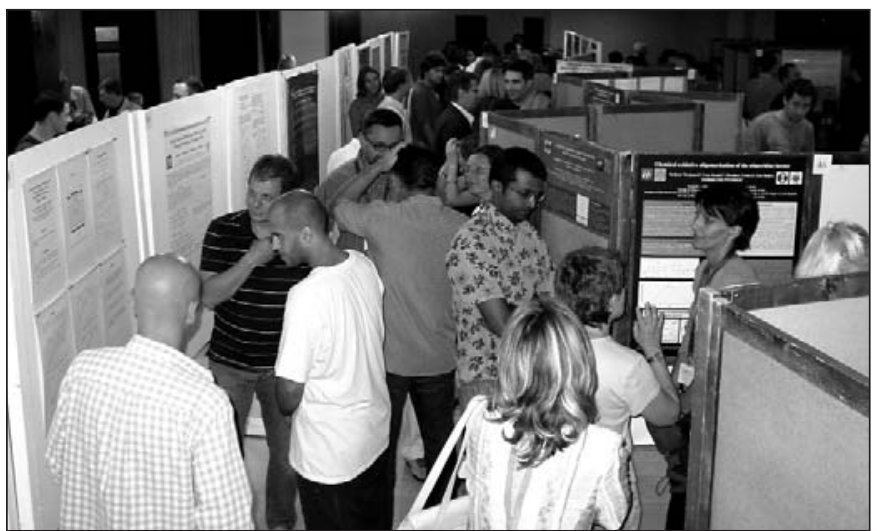

Participants of YUCOMAT 2007 discuss materials research at the Poster Sessions.

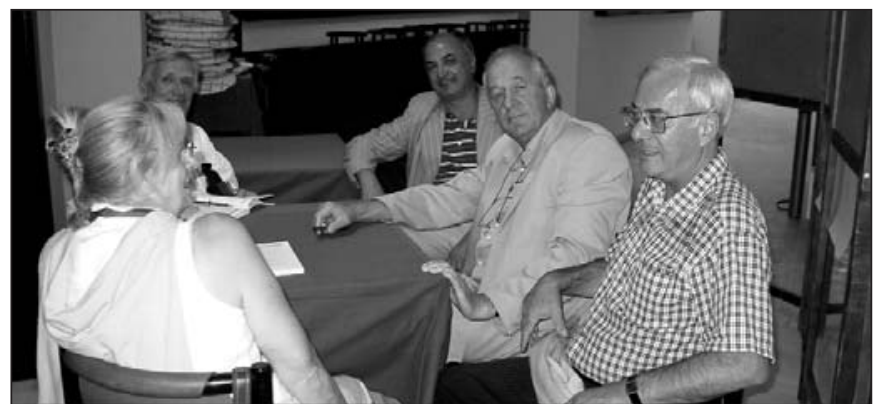

Members of the Awards Committee (from left to right) V. Dondur (Faculty of Physical Chemistry, Belgrade, Serbia), M. Plavsic (Faculty of Technology and Metallurgy, Belgrade, Serbia), D. Rakovic (School of Electrical Engineering, Univ. of Belgrade, Serbia), and M. Davidovic (Institute Gosa, Belgrade, Serbia), discuss awards with the President of Yu-MRS, Dragan Uskokovic (far right).
During the Third Plenary Session, J. Wittig (Vanderbilt Univ., USA) spoke on processing and characterization of magnetic nanostructured materials; J.A. Varela (Universidade Estadual Paulista, Sao Paulo, Brazil) spoke on transport properties of nanostructured antimony-doped tin oxide films; S. Bennici (Institut de Recherches sur la Catalyse et l'Environnement de Lyon, Villeurbanne, France) spoke on NOx abatement over supported binary oxide catalysts containing $\mathrm{CuO}$ coupled with $\mathrm{Ga}_{2} \mathrm{O}_{3}$ and $\mathrm{SnO}_{2} ;$ J.-C. Badot (Ecole

\section{YUCOMAT 2007 Award Recipients}

Best PhD thesis

Nevena Puac (Institute of Physics, Zemun, Serbia), “Development, Diagnostics and Application of Microwave and Radio Frequency Plasma Reactors."

Best MSc thesis

Ivana Stojkovic (Faculty of Physical Chemistry, Belgrade, Serbia), "Structure and Electrochemical Properties of $\mathrm{LiCr}_{x} \mathrm{Mn}_{2-x} \mathrm{O}_{4}$ Synthesized by Glycine-Nitrate Procedure."

\section{Best oral presentation}

Matjaz Spreizer (Institute Jozef Stefan, Ljubljana, Slovenia), "Influence of Crystal Symmetry on the Voltage-Tunability of $\mathrm{Na}_{0.5} \mathrm{Bi}_{0.5} \mathrm{TiO}_{3}$-Based Systems."

Best oral presentation

Vuk Uskokovic (Potsdam University, Clarkson, USA), "Preparation and Multilayered Aggregation of Uniform Colloidal Cholesterol Particles."

Best poster

Marko Virsek (Institute Jozef Stefan, Ljubljana, Slovenia), "The $\mathrm{W}_{18} \mathrm{O}_{49}$ Nanowires Used for Synthesis of the $\mathrm{WS}_{2}$ Nanotubes."

Best poster

Aleksandra Krkljes (Vinca Institute of Nuclear Sciences, Belgrade, Serbia), "Radiolytic Synthesis and Characterization of PVA Hydrogel-Au Nanocomposites."

Best poster

Ana Stankovic (Institute of Technical Sciences of SASA, Belgrade, Serbia), "Effects of Organic Surfactants on Mechanochemically Synthesized ZnO Particles."

Best poster

Bojana Nedic (Faculty of Physical Chemistry, Belgrade, Serbia), "Crystal Structures of Rare-Earth Doped Hexacelsians."

Nationale Superieure de Chimie de Paris, France) spoke on electrical relaxation phenomena in oxides; and G. Lefèvre (Ecole Nationale Superieure de Chimie de Paris, France) spoke on surface reactivity of metal oxides.

The Fourth Plenary Session was opened by M. Remskar (Jozef Stefan Institute, Ljubljana, Slovenia) who spoke on the first inorganic nanobuds and pea-pods. A. Ye. Yermakov (Institute of Metal Physics, Ekaterinburg, Russia) later spoke on synthesis and properties of metal-carbon nanocomposites; X. Batlle (Univ. of Barcelona, Spain) spoke on $\mathrm{Fe}_{3} \mathrm{O}_{4}$ nanoparticles for biomedical application; J. Czernuszka (Oxford Univ., UK) spoke on 3D scaffolds for 3D tissue engineering; and I. Cosic (RMIT Univ., Melbourne, Australia) spoke on bioactive peptide design using the resonant recognition model.

The Plenary lecture of E. Traversa (Univ. of Rome "Tor Vergata," Italy), on nanostructured materials for intermediatetemperature solid-oxide fuel cells, opened the last day of the Conference.

To encourage prospective young scientists, an assigned evaluation Committee selected the authors of the best PhD and MSc theses submitted between the two Conferences, and the best oral and poster presentations (see sidebar).

The next YUCOMAT Conference will be held in Herceg Novi on September 8-12, 2008 (www.yu-mrs.org.yu).

DRAGAN USKOKOVIC President of Yu-MRS and Director of the Institute of Technical Sciences of the Serbian Academy of Sciences and Arts 